\title{
Intermédialités
}

Histoire et théorie des arts, des lettres et des techniques

Intermediality

History and Theory of the Arts, Literature and Technologies

\section{The Photographic Now: David Claerbout's Vietnam}

\section{Ingrid Hölzl}

Numéro 17, printemps 2011

reproduire

reproducing

URI : https://id.erudit.org/iderudit/1005753ar

DOI : https://doi.org/10.7202/1005753ar

Aller au sommaire du numéro

Éditeur(s)

Revue intermédialités (Presses de l’Université de Montréal)

ISSN

1705-8546 (imprimé)

1920-3136 (numérique)

Découvrir la revue

Citer cet article

Hölzl, I. (2011). The Photographic Now: David Claerbout's Vietnam.

Intermédialités / Intermediality, (17), 131-145. https://doi.org/10.7202/1005753ar

\section{Résumé de l'article}

L'installation vidéo Vietnam, 1967, near Duc Pho, reconstruction after Hiromich Mine (2000) de David Claerbout pose la question du photographic now qui désigne aussi bien l'état présent de la photographie que l'état du présent photographique. L'oeuvre reproduit ou, plus précisément, recompose la photographie de presse d'un avion américain abattu par sa propre artillerie. L'artiste belge voyage sur les lieux de l'accident et prend une série de photos du paysage. Il en tire une vidéo à laquelle il superpose l'image de l'avion qui explose en plein ciel, obtenant ainsi une image temporellement hybride et médialement inclassable. Cette étude analyse le processus de reconstruction numérique et d'animation de l'image ; elle s'intéresse au « devenir signal » de l'image et s'interroge sur les possibilités de réactualiser le temps photographique. 


\title{
The Photographic Now: David Claerbout's Vietnam*
}

\author{
INGRID HöLZL
}

$\mathrm{n}$ a recent article investigating a video animation by Nancy Davenport I have put forward the term "the photographic now." The term designates both the current state (the now) of photography and photography's altered relation to time through digital postproduction: montage, collage and animation. I posit that, with the advent of digital postproduction, photographic images are no longer tied to a specific past but show a possible present. As digital images, they are beyond the habitual dualism of still and moving, printed and projected, recorded versus calculated.

The photographic now also reflects the new fluctuating temporality of photographic images through digital screening. The present article seeks to further explore this aspect, taking the example of the video installation Vietnam, 1967 , near Duc Pho (2001) by Belgian artist David Claerbout. In this work, a famous press photograph from the Vietnam war is merged with an animated photosequence taken by the artist at the historical site, converted into a digital video and projected onto the gallery wall. With this, a radically present temporality of the photographic image emerges: a photographic now.

* I am indebted to Rémi Marie for his numerous ideas and comments on the photographic now and on Claerbout's work which helped considerably shape this article, and to the journal's anonymous reviewers and editorial committee for their constructive criticism and suggestions which helped improving it.

1. Ingrid Hölzl, "Blast-off Photography-A Critical Study of the Work of Nancy Davenport," in Photography and Movement, special issue History of Photography, vol. 35, $\mathrm{n}^{\circ}$ 1, February 2011, p. 32-43. 


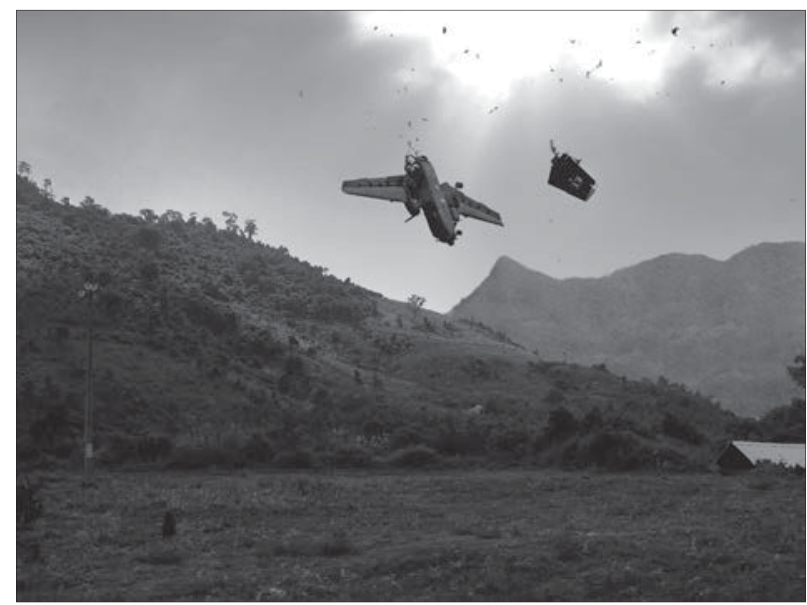

Figs. 1 and 2: Video stills from: David Claerbout, Vietnam 1967, near Duc Pho (Reconstruction after Hiromichi Mine), 2001 single-channel video projection, color, silent, 3 mins. looped. Courtesy the artist and galleries Hauser \& Wirth and Yvon Lambert.

\section{VIETNAM, 1967, NEAR DUC PHO}

Vietnam is a single-channel video installation, silent, and in colour; no information about its dimensions is provided on the gallery preview DVD. When exhibited, the video is projected so as to cover the wall from floor to ceiling. It shows a lush landscape, above which a military plane is displayed in a state of final disintegration. There are subtle changes in light as if clouds were passing over the hills seen in the foreground, whereas the background remains perfectly still resulting in the double oxymoron of the moving still: a still image that is moving and a moving image that is still. ${ }^{2}$ The three-minute loop appears as a continuous take, the light effect simulating the common real-time experience of clouds passing; an experience whose non-narrativity yields the impression of an extended present where "[...] what occurred previously is essentially similar to what is occuring now." 3 A comparison between the two video stills here reproduced serves to highlight the quasi-static nature of the video; though sampled from different moments in the piece, the two stills look strikingly similar (see Figs. 1 and 2).

2. Ingrid Hölzl, "Moving Stills-Images that are No Longer Immobile," in Photographies, vol. 3, n ${ }^{\circ}$, April 2010, p. 99-108.

3. David Claerbout and Lynn Cooke, "Conversation," in Kurt Vanbelleghem (ed.), David Claerbout, Bruxelles, A Prior, 2002, p. 52. 


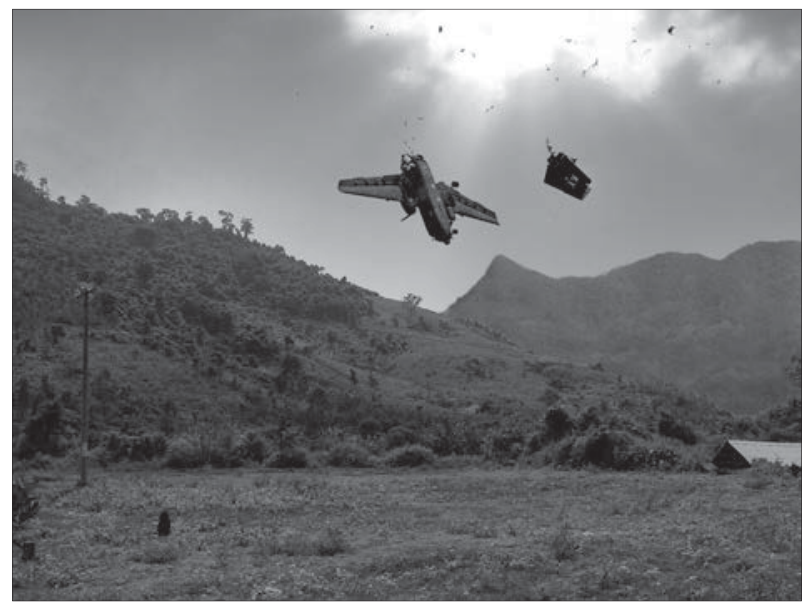

The full title of the installation, Vietnam, 1967, near Duc Pho (reconstruction after Hiromichi Mine), provides the viewer with a considerable amount of historical information: where, when and by whom the image, which the present work is meant to reconstruct, was taken. Exploring the reference given in the title, we uncover Hiromichi Mine's identity as a Japanese press photographer who worked for United Press International during the Vietnam war. Mine took the photograph in 1967 , one year before he died, when the armoured personnel carrier he was in hit a land mine in central Vietnam. The photograph is included in a book entitled Requiem, ${ }^{4}$ which celebrates the work of the 135 photographers who died or went missing in Indochina, Vietnam, Cambodia and Laos in the period spanning 1950-1975. The caption of the double-spread runs as follows:

Ha Phan [sic], Vietnam, 1967. A U.S. twin-engine transport Caribou crashes after being hit by American artillery near Duc Pho on August 3, 1967. U.S. Artillery accidentally shot down the ammunition-laden plane, which crossed a firing zone while trying to land at the U.S. Special Forces camp. All three crewmen died in the crash. ${ }^{5}$

Claerbout has established his reputation as an artist whose video installations, located at the crossroads between film and photography, question the specificities of the filmic and the photographic image. The issue in Vietnam, notes David Green, is "not the conflation of photography and film but a conjuncture

4. Horst Faas and Tim Page (eds.), Requiem-By the Photographers who Died in Vietnam and Indochina, New York, Random House, 1997.

5. Ibid., p. 189 . 
of the two media in which neither ever loses its specificity." ${ }^{6}$ But, as Claerbout himself puts it, "What should be done with the solid looking' aspects of both film and photography in a computer-based environment? And, what becomes of the image as it is processed by one and the same electronic signal from its encoding to its output as a video- or data-projection?"7

Rather than updating the critique of medium specificity prevalent in the critical writing on Claerbout with another layer of complexity, we need to address the questions raised by this loss of medium specificity. During the first seconds, the projection seems to be a still photograph. It is only after some time that slight changes of light allow the viewer to scrutinise the image in order to grasp its status: if it is moving, it is a video, if not, it is a photograph. But the work resistsit does not yield an easy answer, and the medium uncertainty remains.

Noël Carroll has stressed that "if you know that what you are watching is a film, even a film of what appears to be a photograph, it is always justifiable to expect that the image might move." ${ }^{\text {T }}$ The point here is that we do not know whether what we are watching is a film that appears to be a photograph or a photograph that appears to be a film. We do not know whether we should wait for movement to reveal the image to be a moving image or, rather, wait for stillness to reveal the image to be a still image. The changes of light that become perceptible after some time generate the sensation of time passing, thus, of viewing a moving image. But these changes are rather minimal, forcing the emergent moving image back into the state of almost-stillness.

The stake of the video, one might say, is the "nothing to see" in the sense that, despite the filmic expectation of the viewer in front of a projected image, nothing moves: not a leaf, not a cloud, not a sound. When finally the viewer resigns herself to the prospect that this tension between movement and stillness might remain unresolved, she may resort to simple enjoyment of the landscape's silence, its interplay with the light, and the ambivalent sensation of time passing. Continuous observation of a peaceful landscape where time passes but nothing much happens generates a contemplative mood. In front of this postmodern vanitas, the viewer is invoked to meditate on time.

6. David Green, "The Visibility of Time," in Susanne Gaensheimer, Friedrich Meschede, Frank Lubbers, and Katrina Brown (eds.), David Claerbout. With two essays by David Green, Cologne, Verlag der Buchhandlung Walter König, 2004, p. 21.

7. Claerbout and Cooke, 2002, p. 42.

8. Noël Carroll, "Towards an Ontology of the Moving Image," in Cynthia A. Freeland and Thomas E. Wartenburg (eds.), Philosophy and Film, New York, Routledge, 1995, p. 73 . 


\section{AFTER CLAERBOUT}

As stated above, the photographic now pertains to the new temporality of the photographic image arising from the processes of digital postproduction and screening. Postproduction is at play in Vietnam in the form of both digital animation and collage. Fragments of the Mine photograph are seamlessly merged with newly photographed imagery of the historical site in order to achieve a powerful composition. Comparing the "Requiem" version of the Mine photograph with a still of Claerbout's piece, one notices several subtle differences, all of which aim to increase the dramatic impact of the picture.

While the hills in the foreground have changed, those in the background remain exactly the same (by enlarging the still, the raster grid of the newsprint photograph becomes visible). In the foreground, the American artillery camp is replaced by a lush landscape. The military antenna on the left is replaced by a telegraph pole and electric wires. On the right edge of the image, a building with a metal roof resembles that in the historical photograph, with the exception of some details. The body of the plane is moved up and to the right, closer to the cut-off tail. The debris is concentrated into a light zone of the sky above and to the right of the plana; in the Mine photograph the sky is of a uniform grey.

In his conversation with Lynn Cooke, Claerbout explains that "in order to make Vietnam, 1967, near Duc Pho (2001), I went to the place where Hiromichi Mine had been, but as I was not able to place myself in the same position I had to recompose the photograph somewhat." In a recent email conversation I had with the artist in May 2010, he elaborated upon this point:

I did indeed travel to the same spot but I couldn't locate the exact spot. Things just didn't look quite the same. After a few days I learned that this landscape had been dramatically changed by bombings (the hills) and by a layer of several meters to cover the old air strip when the Americans left so as to make it no longer usable as a landing strip. The landscape was recorded with a consumer still camera, recording one image every 2.5 to 3 seconds. As such, a change of light can be noticed via the sequence of several hundreds of stills taken one after the other. Then, through simple "crossfading," the stills were animated. [...] Also, the sky was newly photographed. It is non-moving; so, a still. ${ }^{10}$

The video is thus composed of several layers. The background is a video image fabricated by crossfading a photo series taken by Claerbout somewhere

9. Claerbout and Cooke, 2002, p 62.

10. This email conversation took place between Friday May 14 and Monday May 17, 2010. 
around the historical site. A re-photographed sky, at the center of which there is a lighter-coloured zone, is then superimposed over this background. The third layer consists of the hills in the background and the parts of the exploded airplane taken from a newspaper print of the Mine image. The body of the plane is repositioned right below the lighter area of the re-photographed sky, as if this zone emanated from it in the form of a white cloud.

In order to bring together the different elements of this moving image collage into a single coherent view, the changes of light of the photo-animation are digitally extended to the aircraft so that, when viewing the projection, the whole image seems to be invested with subtle changes of light. When viewing the video in fast forward, the different layers of the collage become palpable, as well as the partial animation: the light effects focus on the hills in the foreground and on the plane, but do not affect the hills seen in the background and the rest of the sky. ${ }^{11}$

\section{AFTER MINE}

Claerbout's complex digital recomposition questions the very possibility of what it pretends to be: the reconstruction of a photographic document. The composite, yet authentic, image also questions the possibility of photographic documentation as such. It questions the assumption of a direct causal relation between event and image, an assumption that is based on an indexical understanding of photography as the self-imprint of reality on a photosensitive surface. It questions the capacity of the camera to accurately capture an event and the capacity of the image to faithfully transmit this event through time and space. Photographic authenticity, or originality, is commonly understood as a relation of faithfulness: between object and negative, negative and print, original print and reprint.

Philosophically, this common belief has been formulated by Kendall Walton in terms of "transparency" or as the "counterfactual dependence" of the effect (the photographic image) on the cause (the photographed object). ${ }^{12}$ This notion rephrases Charles Sanders Peirce's semiotic notion of the physically

11. The "fast forward" display is another instance of the new fluidity of photographic time generated by digital technology as a kind of response to the new malleability of filmic time generated by analogue video technology. See Mary-Ann Doane, "Real Time: Instantaneity and the Photographic Imaginary," in David Green (ed.), Stillness and Time: Photography and the Moving Image, Brighton, Photoworks/Photoforum, 2006, p. 23-38.

12. Kendall L. Walton, "Transparent Pictures: On the Nature of Photographic Realism," in Scott Walden (ed.), Photography and Philosophy: Essays on the Pencil of Nature, Malden, Blackwell, 2008, p. 14-49. 
forced "point-to-point resemblance"13 between object and image. Patrick Maynard, again, has proposed the notion of "seeing-in" or "factive pictorial experience"14 which relates to Barthes's notion of the "that-has-been"15 (ça a été) of the photographed object.

"If everything works as it should," writes Maynard, that is, "if the aim of the photographic apparatus to produce an accurate image of the world is respected, the resulting image allows to deduct the factivity of the object that it shows." ${ }^{16}$ In the case of the digital photograph, the first instance of the "chain of information," the negative, is missing. As a result, one may think that the direct relation of object and image is even more direct than was the case in analogue photography; however, Maynard argues that this is not so. With digital recording, the "chain of information" between object and image is contrived. Most digital cameras interpolate, adding information that is merely assumed as "having been there" in front of the camera lens. Maynard has a point here, but it can be argued that the chain of information (starting with the photographed scene) is equally contrived in analogue recording. Optical and chemical parameters, photographers' and printers' decisions, etc., influence which information is transmitted and passed on to the photographic image and which information is omitted. Thus, the lossfree "chain of information" from object to image to viewer that Maynard posits as a general rule is a purely theoretical concept.

The common understanding of photography as a transparent medium allowing for "seeing in" means that event and image are mutually authenticated in a circular argument: there has been an event because it has been faithfully captured by a camera which is meant to faithfully capture an event. Mine's photograph is famous for having captured a singular event: the explosion of the Caribou plane near Duc Pho on August 3, 1967. But how can we know for certain that the image is a single view of this singular event? Could it not be a collage, such as Frank Hurley's collages of WWI? If we accept the assumption that a capture of a singular event has indeed occurred, the different versions of the image raise another question: what constitutes the event here? The contact of

13. Charles Sanders Peirce, "What is a Sign?", in The Peirce Edition Project (eds.), The Essential Peirce, Vol. 2: Selected Philosophical Writings (1893-1913), Bloomington, Indiana University Press, 1998, p. 4-26.

14. Patrick Maynard, "Factive Pictorial Experience: What's Special about Photographs?" Nous (forthcoming 2012).

15. Roland Barthes, Camera Lucida: Reflections on Photography, New York, Hill and Wang, 1981, p. 63-119.

16. Maynard, 2012. 
the missile with the plane? The explosion of the plane? Its final crash? The event itself, one could say, has already happened; it is only its aftereffects that we see, the destroyed plane and the debris, suspended in separate points in space, before continuing along their separate paths down to earth.

The answer is that the "decisive moment" is not the representation of an event, but rather the conception of an event and its representative moment. (The famous photograph of the Hindenburg explosion, for example, shows the very moment of the explosion of the airship.) The camera does not capture an event, but creates a photographic event. It depicts a moment that has never existed as such. The photograph does not reveal the optical unconscious, but rather the photographic unreality: it shows what does not exist prior to the photographic event, i.e. the photograph. The causality argument commonly invoked with photographs holds that the recording exists because of the recorded. Instead, the opposite seems to be the case: the recorded exists because of the recording.

\section{RECONSTRUCTION, RECOMPOSITION, REACTUALISATION}

The version of Hiromichi Mine's photograph published in the Requiem book differs significantly from three others that I was able to locate online: one on the World Press Photo website, and two on the website of the C-7A-Caribou association. The World Press Photo, whose frame is almost rectangular, centres on the American artillery camp; the plane appears towards the left. In the Requiem version, larger in frame, the plane is in the centre of the image, with the horizon line dividing the image into two equal parts: the foreground with the camp and the sky with the plane. In the first Caribou version, apparently reproducing the Requiem version, the plane is still at the centre of the image, but the horizon line is considerably higher, showing more of the American camp. Also, the contour line seems to be retouched, giving it a strangely concave shape. In the second Caribou version, the horizon line is lower again, showing more of the sky and less of the camp. Most importantly, the frame is shifted to the right. The plane appears far left. Far right, large pieces of debris in the sky come into view. What appears to be the edge of a shed in the other three versions is revealed to be the remnants of a church with a clock tower.

Vietnam is closest to the Requiem version of the Mine photograph, which means that the artist most probably used this version as the model for his reconstruction. But the considerable differences in terms of light, framing, and internal composition raise the question of what Claerbout reconstructed exactly. The event of the Caribou crash, its photographic documentation, his own experience 
of the photograph, or his search for the exact viewpoint from which Mine shot his famous photograph? Why should one want to reconstruct a perfect shot? It seems, rather, that Claerbout used Mine's photograph to reconstruct the deceptive landscape he was confronted with, a landscape that hides its violent past under peacefull hills. The landscape was actually reconstructed by the American soldiers when they left, the airstrip covered so as to make it no longer usable for the Vietnamese. Can Vietnam thus be a reconstruction of the past by means of the present or is it, on the contrary, a reconstruction of the present by means of the past?

The caption "After Hiromichi Mine" places Claerbout's video animation in relation to Mine's press photograph and thus comments on the relationship between original and remake. But taken literally, "after Mine" indicates a relation of time. Thirty years after Mine, Claerbout, the Requiem print in his hand and the idea of its reconstruction in his mind, travelled to the historical site. But, as he was not able to take Mine's position, he "had to recompose the photograph somewhat." ${ }^{\prime 7}$ As I have shown, the artist indeed recomposed the Mine imagenow consisting of at least three different layers-quite substantially. Referring to his working method in general, we can assume that even if the landscape had not changed and Mine's point of view still existed, Claerbout would have recomposed the image.

In his conversation with Lynn Cooke, the artist speaks of "creating a strong composition, [a] schematic framework that [...] determines the way that one remembers [a piece]." ${ }^{18}$ To increase its impact, Claerbout uses "theatrical elements, like 'real' duration, and life-size projection." ${ }^{19} \mathrm{He}$ associates his practice of recomposition with that of history painting, in opposition to newsreel footage where "the camera chases after events: the composition is focused and locked into whatever is considered news." ${ }^{20}$ More interested in a strong composition than a strong message, Claerbout converted the still image of the past, depicting an impossible event (an event that has taken place only as a photograph), into a moving image of the present depicting a possible landscape. At the same time, the artist attached great importance to the resemblance of image details, such as the shed on the right edge of the frame, which replaces a similar item in the

17. Claerbout, 2002, p. 62.

18. Ibid.

19. Ibid., p. 53.

2o. Ibid., p. 62. 
earlier photograph, or the telegraph pole on the left side, which, in turn, replaces an antenna.

Claerbout's pilgrimage to the very location of the crash reminds us of Tacita Dean's audio piece, Trying to Find the Spiral Jetty (1997), which documents her search for Smithson's famous earthwork. Dean followed the precise instructions that Smithson left to locate the Spiral Jetty, but failed to find it. In both cases, the delay between the initial act (of making an earthwork, of making an image) and the act of its intended re-enactment is approximately 30 years. Claerbout very probably procured a set of instructions similar to those Dean had in order to find the location of the American camp (and we can assume Claerbout knew about Dean's work when he embarked on this project a few years later).

Let us briefly imagine the artist travelling to Duc Pho with his GPS device. Google maps will yield no more information than the name and a highway passing through. Let us imagine him asking people and placing the photograph between himself and the landscape, resorting to a kind of Brunelleschi experiment in order to exactly match image to landscape. ${ }^{21}$ As has been stated in the case of Dean's work, "it appears that the enactment of the instructions is more important than the attainment of the goal." ${ }^{22}$ But the instructions given by Mine are limited to the photograph. Contrary to Dean, who was ultimately unable to find the location of the Spiral Jetty at all, Claerbout did find the location of the American base, but he was unable to reconstruct the exact position from where Mine had taken his famous photograph-for the simple reason that this position no longer existed as the landscape had been changed by the Americans.

While Dean's piece is the audio document of her failed search, Claerbout's piece is the video document of his failed find, his failed attempt to find the "reality then" in the "reality now," his failed attempt to reactualize the past. Or, rather, it is the visual recording of the necessary failure to reactualize the past, a failure that is most likely part of the work itself. For it is precisely the difference between the "landscape then" and the "landscape now" that allows for the sensation that time has passed and that the past is irretrievably past-even if the still image of the "landscape then" is digitally animated and merged with the moving image of

21. The Brunelleschi experiment demonstrated the match between natural and artificial perspective. The viewer had to take the same point of view from where the image had been painted. Through the image being reflected in a mirror, the viewer could see a continuum of reality and representation.

22. Juan Cruz, "Disrupting the Scene: Fiona Banner, Pierre Bismuth, Fiona Crisp, Tacita Dean," Contemporary Visual Arts, n² 21, 1999, p. 76. 
the "landscape now," which seems to convert the time past and the time that has passed into the passing of time now.

As Walter Benjamin posits, the past is incommensurable with the present and remains irrefutably past. It cannot be reactualized in the present, as being present. It can be seized only as an image "that flashes up at the moment of its recognizability, and is never seen again." 23 "For while the relation of the present to the past is a purely temporal, continuous one, the relation of what-has-been to the now is dialectical: is not progression but image, suddenly emergent." 24

What is at stake in Vietnam is this impossibility of seizing the past in an image that lasts. At the same time, what is at stake in Vietnam is this impossibility and its reversal; if one cannot reactualize the past, one can, however, reactualize the present. In The World Viewed, Stanley Cavell argues that the "presentness" of the world past is due to the succession of world projections. ${ }^{25}$ With digital video projection, these world projections are no longer film frames, but video frames. They are no longer spatial units of a discontinuous film strip, but temporal units of a continuous video signal. ${ }^{26}$ With this, the paradoxical temporality of film as "the projection of the world past that is present to us while we are not present to it" 27 is being recast as the present temporality of the digital image that is present to us as we are present to it. With digital video projection, what is reactualized with each new frame is not the world past, but the present (continuous) image.

\section{SCREENING STILLNESS}

With digital screening, the still image is nothing more (or less) than a liminal state of the moving image. In its default mode, the digital video signal is

23. Walter Benjamin, "On the Concept of History (1940)," in Howard Eiland and Michael W. Jennings (eds.), Selected Writings, Vol. 4, Thesis V, Cambridge, Harvard University Press, 2003, p. 390-391.

24. Walter Benjamin, The Arcades Project (1927-1940), trans. Howard Eiland and Kevin McLaughlin, Cambridge (Mass.), Harvard University Press, 1999, p. 462.

25. Stanley Cavell, The World Viewed: Reflections on the Ontology of Film, Cambridge (Mass.), Harvard University Press, 1979, p. 40.

26. Contrary to the frame in photography and film, the video frame is a completely linear scan of a picture; it is thus a "processual image" (Spielmann). Both analogue and digital video are electronic signals, but since digital video derives from numerical code, it offers more possibilities in terms of signal processing. See Yvonne Spielmann's notion of "transformation imagery" in her seminal study Video: The Reflexive Medium, Cambridge (Mass.), MIT Press, 2008.

27. Cavell, 1979, p. 40. 
continually changing while building up its 50 half-frames. ${ }^{28}$ With every new frame-that is, every $25^{\text {th }}$ of a second-the image changes. In the case of the still image converted to digital video, the image does not change. It is, however, continually updated according to the video frame rate and the refresh rate of the video projector: 25 and 60 times per second respectively. ${ }^{29}$ While the refresh rate indicates how often the projector draws the data (be it the same or different), the frame rate indicates how often the video source is producing an entirely new image (be it the same or different). Thus, the still image represents a special case of the moving image. It is a moving image that does not move. As such, it represents an anomaly, if not a risk for the screen that has been made to display moving images. ${ }^{30}$

With digital screening, stillness is no longer a medium-immanent quality, but rather an optional display mode of the digital video signal, whose default mode is movement. Put differently: stillness and movement are no longer properties of a given medium, but two modes, changing and repetitive, of an electronic signal. In this sense, Vietnam is ironically historical, since press photography has contributed to the conversion of the photographic image from sign to signal

28. So far, analogue and digital video technology operated with interlaced halfframes or fields: two fields correspond to one complete scan of a picture; the European PAL standard is 50 interlaced fields (50i), the American NTSC standard is 6oi. Claerbout's video installation uses the European PAL standard (50i): 50 fields or 25 frames per second.

29. As the video frame rate increases, so does the refresh rate of computer monitors, which indicates the number of times in a second that the display hardware draws the data. The standard refresh rates for analogue TV and computer monitors used to be approximately $60 \mathrm{~Hz}$ (which indicates the frequency of the wavelength), although this standard is continually increasing, as the higher the rate, the less strain for the eye. With digital LCD displays used for most portable screens, activated LCD pixels do not flash on/off between frames, so there is no refresh-induced flicker, no matter how low the refresh rate is.

30. This is reflected by the now technically obsolescent screensaver programs which were supposed to prevent so-called burn-ins in CRT monitors if the image remained too long unchanged. As Nancy Davenport has pointed out, by the time screensavers were becoming ubiquitous, their technical necessity had already been superseded. See Nancy Davenport, "Artist Questionnaire," October, vol. 100, Spring 2002, p. 58-61. With LCD monitors, screensavers are even inimical to the screen; they do not save it but reduce its lifetime since the fluorescent backlight remains lit. Yet, even today, screensavers are a default mode of virtually any personal computer display. The function of the screensaver, it seems, has never been to fix a technical shortcoming, but rather to distinguish active screen time from "idle time," and to mark this "idle time" through an (in)aesthetic difference: the wavering colour lines. 
through electronic image processing, transmission, and display-time consuming then, instantaneous today.

With digital animation, the immobility of the photograph is only temporary; "the image can be reanimated at any moment." "It is what I have called elsewhere a potentially moving image..$^{32}$ In Vietnam, Claerbout animates a still image sequence by "simply crossfading," 33 into a moving image, and the still-still image of the plane by means of a digital effect into a moving-still image. Druta Veaceslav speaks of Claerbout's method (and more specifically of the Shadow Piece) in terms of hybridisation..$^{34}$ Technically, hybridisation is produced by an effect of incrustation whereby an image is superposed onto another. Following Veaceslav, this term aptly describes what one sees, namely "l'incrustation d'un matériel fluide, la vidéo, dans un matériel solide, la photographie. Cette impression est seulement à l'écran. Dans l'ordinateur, au moment de leur rencontre, la photographie et la vidéo sont déjà tous les deux transformées en code, flux, courant." ${ }^{15}$ Whereas the mind still holds onto a bygone difference of media-still versus moving-the digital signal that produces the sensation of stillness and movement is already the same.

Whereas a filmic freeze frame has always been perceptively undistinguishable from a projected photograph, their respective adherence to different technologies and temporalities of projection (film projector versus slide projector, still versus moving) has made them media theoretically distinct: the freeze frame is filmic, and the projected photograph is photographic. With digital screening, this possibility no longer exists. The digital video signal that is projected or displayed on the screen carries both still and moving image content. On the screen, the photographic image no longer appears as a projected photograph, but as the evocation of a photograph.

David Green defends the idea that Claerbout's video projection does not demonstrate the "eroding of boundaries between media," and that "what one sees in this work is not the conflation of photography and film but a conjuncture of the two media in which neither loses its specificity," the screen providing "a

31. Rudi Laermans, "The Process of Becoming an Image," in Vanbelleghem, 2002, p. 19.

32. "Photography and Movement," introduction to Hölzl, 2011, p. 4.

33. Email conversation, May 2010.

34. Druta Veaceslav, "Des transformations de la photographie dans Shadow Piece et autres vidéos de David Claerbout," e-AdNM, 26 January 2008. This text can be found at www.arpla.fr/canal2o/eadnm/?p=46 (last accessed December 5, 2010).

35. Ibid. 
point of intersection for the photographic and the filmic image." ${ }^{36}$ But what intersects on the screen is not the photographic and the filmic image; it is only their respective evocation in the form of the digital image. What the screen shows is an image that is already one step beyond medium specificity. Green interprets Vietnam as presenting, with the still photograph and the moving image, two conflicting modes of representation. But Vietnam is already indifferent to this conflict. As a digital moving image collage, it pertains to the photographic now which is characterized by the new modes of production and display induced by digitalization, postproduction and screening, and by the new fluctuating temporalities of the image that they foster.

In this sense, Vietnam is neither a photograph nor a film, it is the image of an image, an afterimage, so to speak. What Vietnam shows is not a photograph by Hiromichi Mine, not even a part of it, but a possible image of that photograph. Put differently, what one sees is the Hiromichi Mine photograph as a digital stilllife, providing the art historical term with a new meaning and a new temporality. ${ }^{37}$

In layering "the trapped present over the trapped past of the photograph,"38 Vietnam seems to constitute a perfect image-trap, the contemporary version of the Vexierbild. By projecting the image of the present onto the image of the past, it seems to overcome the historical distance of the latter and to directly affect the viewer in stimulating a contrived recollection. But, in effect, the contrary is the case: the image of the past is projected onto the present to make the latter intelligible. Vietnam is not a reconstruction of the past by means of the present but a reconstruction of the present by means of the past. In Vietnam, Claerbout

\section{Green, 2004, p. 21.}

37. What is usually overlooked is the oxymoron of the term; fruits and flowers (life) are represented as if they were inanimate (still) and, thus, beyond the reach of time. For these perishable objects to appear in the same state during the days and months of painting the picture, they need to be continually replaced. Claerbout's interactive computer work, Present (2000) deals precisely with this real-time decay, eclipsed by the painterly fixation. A computer program, once installed on a computer, delivers the real-time image of the decay of a flower on its desktop. The decay, of course, is pre-recorded and occurs exactly in the same manner on any computer to which the program has been downloaded. But the impression of assisting a real-time event persists; the temporality of the decay cannot be altered; the duration of the recording and the replay correspond exactly to the duration of the event. Sara Tucker, "Introduction to Present," Dia Art Foundation, 9 November 2000. See www.awp.diaart.org/claerbout/intro.html (last accessed December 5, 2010).

38. Damien Sutton, "The New Uses of Photography," in The Crystal Image of Time. Photography, Cinema, Memory, Minneapolis, University of Minnesota Press, 2009, p. 224. 
projects the image of the past onto his own experience of the present; only then can this experience become image.

The photograph, writes Barthes, points to a past event as though it was about to occur in the present and makes us "shudder, like Winnicott's psychotic patient, over a catastrophe that has already occured." ${ }^{39}$ Through the processes of digital postproduction and screening, this psychotic affect induced by photographic technology and the structure of visual recognition and memory is blocked. With the photographic now, a new, radically present temporality of the photographic image emerges. We are no longer experiencing the conflicting temporality of the past present, but the continuous temporality of the digital present. What is reactualized is not the image of the past but the present image, a continuously refreshed digital video signal: presence 25 times per second, life 25 times per second.

39. Barthes, 1981, p. 96. This peculiar experience of the past as future is triggered by Barthes's acute chagrin after his mother's death. When going through her things, he finds a picture of his mother as a child, the famous winter garden photograph which stands at the core of the second part of Camera Lucida. In his Journal de deuil, written while preparing the book, Barthes mentions: "13 juin 1978 [...] Ce matin, à grande peine, reprenant les photos, bouleversé par une où mam. petite fille, douce, discrète à côté de Philippe Binger (Jardin d'hiver de Chennevières, 1898). Je pleure. Pas même envie de me suicider." In an earlier entry he notes: "10 mai 1978. Depuis plusieurs nuits, images cauchemars où je vois mam. Malade, frappée. Terreur. Je souffre de la peur de ce qui a eu lieu. Cf. Winnicott: peur d'un effondrement qui a eu lieu." Roland Barthes, Journal de deuil 26 octobre 1977-15 septembre 1979, Nathalie Léger (ed.), Éditions du Seuil, coll. «Fiction \& $\mathrm{C}^{\mathrm{ie}}$ », 2009, p. 133, 155. 
